\title{
La enseñanza de la filosofía, una necesidad en la formación humanística
}

\author{
The teaching of philosophy, a necessity in humanistic training
}

Caszely Orlando Rivera Huarancca ${ }^{1}$

criverahu@unmsm.edu.pe

https://orcid.org/0000-0001-9548-9678

Universidad Nacional Mayor de San Marcos, Perú

\section{EDMUNDO JOSÉ ROJAS GALINDO²}

erojas@une.edu.pe

https://orcid.org/0000-0002-1884-096X

Universidad Nacional de Educación, Perú

\section{RESUMEN:}

La presente investigación analiza dos variables referidas a la capacidad pedagógica que posee el docente que enseña filosofía, la capacidad de enseñanza puede resultar unilateral a un ejercicio de análisis pedagógico; sin embargo, resulta valioso, el análisis por el efecto que posee la enseñanza de dicha materia en la formación humanística del estudiante. El método utilizado es la investigación documental como un estudio sistemático acerca de las variables enseñanza y enseñanza de la Filosofía. El estudio nos llevó a formular, tentativamente, un conjunto de capacidades que los estudiantes pueden lograr, siempre que el docente actúe oportunamente y gestione su accionar pedagógico con solvencia académica.

\section{ABSTRACT:}

The present investigation analyzes two variables referred to the pedagogical capacity that the teacher who teaches philosophy possesses, the teaching capacity can be unilateral to an exercise of pedagogical analysis; However, the analysis is valuable due to the effect that the teaching of said subject has on the humanistic formation of the student. The method used is documentary research as a systematic study about the teaching and teaching variables of Philosophy. The study led us to tentatively formulate a set of capacities that students can achieve, provided that the teacher acts in a timely manner and manages their pedagogical actions with academic solvency.

\section{Palabras Clave:}

Estudio sistemático; enseñanza de la filosofía; humanismo; pedagogía.

\section{KEYWORDS:}

Systematic study; philosophy teaching; humanism; pedagogy.

Recibido: 31/07/2021 - Aceptado: 10/10/2021 - Publicado: 23/12/2021

\footnotetext{
(C) Los autores. Este artículo es publicado por la Revista peruana de investigación e innovación educativa de la Facultad de Educación, Universidad Nacional Mayor de San Marcos. Este es un artículo de acceso abierto, distribuido bajo los términos de la licencia Creative Commons Atribución 4.0 Internacional (CC BY 4.0) [https://creativecommons.org/licenses/by/4.0/deed.es] que permite el uso, distribución y reproducción en cualquier medio, siempre que la obra original sea debidamente citada de su fuente original.
} 


\section{Introducción}

El hombre en su devenir social ha creado diversas instituciones con determinados propósitos, entre ellos, la universidad. A esta acuden generaciones de jóvenes y personas con la determinación firme de alcanzar una cualificación para insertarse en la sociedad y contribuir a su bienestar. Otros, acuden a la universidad para mejorar sus competencias en el mundo laboral donde realizan alguna actividad.

El nuevo entorno económico, político, tecnológico y científico exige mayor eficiencia a la universidad. La universidad como la mayor expresión académica de formación humanística y científica, como sostiene Homer Haskins, es producto de la Edad Media europea y es una organización que en la actualidad es promotora del conocimiento, y la investigación.

De acuerdo con Hastings Rashdall, profesor de la Universidad de Oxford y autor de la ya clásica obra, las Universidades de Europa en la Edad Media (1895), se afirma que la idea propiamente dicha de universidad, es esencialmente medieval, y en la actualidad, se observa que esa idea de universidad continúa todavía dominando nuestros modernos sistemas universitarios (Tünnermann, 2003, p. 15).

\section{Aristóteles y la enseñanza}

Aristóteles, fue discípulo de Platón durante veinte años (desde los 17 años, hasta la muerte del Maestro). Platón no practicó un riguroso sistema científico, ni método, de enseñanza; sin embargo, por su vastedad teórica pasó al espacio clásico del mundo de la Filosofía. Alguna vez, Nietzsche lo calificó de "precristiano" por sus anticipados postulados teológicos y morales.

Aristóteles con el auspicio de Alejandro Magno fundó el "Liceo o Gimnasio de Atenas" en el año 335 a.C. Dicha escuela es considerada como la antesala a la universidad, que se crearía siglos más tarde. Aristóteles, en su escuela, promovió la ciencia y modeló sus criterios a las exigencias de los estudios científicos (Montanelli, 1985, p.238).

Entendió la necesidad de formar equipos para llevar a cabo estudio pues el compartir conocimientos como habilidades es una necesidad mutua en el proceso de la investigación. Reunió a sus alumnos en grupos y les confió responsabilidades académicas: unos recogían y catalogaban los órganos y las costumbres de los animales, otros hacían lo mismo con las plantas, y otros, compilaban el devenir del pensamiento científico. Su pensamiento discurría en la inducción razonada sobre hechos experimentales. Aristóteles organizaba sus escritos dándoles sentido a las palabras para así construir sus enunciados. Explica que son definiciones, categorías, tiempo, materia, movimiento, entre otros. Este personaje fue el verdadero profesor.

En Aristóteles se percibe los antecedentes de un profesor de universidad, por el carácter sistemático con que se aborda la enseńanza de una materia académica y la actividad investigativa. Otro aspecto relevante que promueve la enseñanza de la Filosofía es la formación humanística. Entonces, surge la necesidad que el docente de Filosofía promueva el pensamiento crítico, el accionar ético entre los estudiantes y puedan estar aptos para comprender y cambiar su entorno con un único propósito, el bienestar de la sociedad; así como, el respeto por la diversidad cultural y el medio natural.

\section{La enseñanza}

La enseñanza cumple un papel importante en el proceso del aprendizaje, prima su atención en promover procedimientos oportunos para trasmitir conocimientos planificados y pensados que respaldan el perfil profesional que en su proceso académico alcanzarán los estudiantes. La enseñanza universitaria se distingue por la producción y valorización de nuevos conocimientos. En ese sentido, revisamos conceptos de enseñanza que describen la naturaleza teórica e importancia que posee en el proceso educativo. 
En primer lugar, referimos a Sócrates quien se refiere a la enseñanza como proceso académico que data de los inicios del siglo de Sócrates, y que Platón refiere que da gracias a Dios por haber nacido en dicho tiempo. El mismo Sócrates, en el siglo IV a. C., a través de su método dialéctico refleja una forma de su magisterio que tenía como objeto realizar una visita guiada por la razón era una forma de enseńanza que consistía en la realizaciónde preguntas que lograban la reflexión en la persona interrogada descubriendo por sí mismo la verdad (Gambra, 1989, p. 63). La enseńanza socrática promovía la reflexión de la persona para aterrizar tentativamente en la verdad. La verdad en el espacio académico se vincula con el conocimiento y el nivel de conciencia alcanzado por el estudiante.

De Cols (1976) evidencia que la enseñanza es un proceso continuo de toma de decisiones, con el objeto de crear las condiciones que conduzcan a los estudiantes a lograr los objetivos propuestos (p. 20). La toma de decisiones se entiende como el acto inteligente del docente que busca enseñar para transformar mentalidades.

Álvarez (1984) sostiene que la enseñanza responde al "cómo" del proceso académico y su propósito es que se produzca de manera oportuna y pertinente la interacción entre los estudiantes, la dirección del profesor y los contenidos establecidos oportunamente en el sílabo, para que se logre los objetivos de aprendizaje o las competencias establecidas, esto último responde al modelo educativo que tiene la casa de estudio (p. 163). La enseńanza exige planificar el acto educativo en concordancia con las competencias u objetivos de aprendizaje.

Freire (2004) explica que enseñar exige de rigor metódico y el educador democrático en su práctica pedagógica debe reforzar la capacidad crítica del educando, su curiosidad, su insumisión. El objeto cognoscible debe estudiarse a profundidad, es decir, debe conectar el objeto de estudio con la realidad y así superar el mecanicismo de la memorización y las especulaciones del pensamiento (pp. 13-14). El docente debe conocer y aplicar el método apropiado a la enseñanza de la filosofía para provocar el aprendizaje y la reflexión del estudiante.

Perkins como se cita en Tobón (2015, p. 83) recurre al escenario de la psicología cognitiva para explicar la enseñanza. En estos tiempos se ha superado la concepción de la mente humana como concepción-capacidad a la teorización representación-contexto, el énfasis está puesto en las estrategias y procesos representacionales; se intenta comprender como las personas nos representamos a nosotros mismos, la realidad y los demás. La psicología como ciencia complementaria a la educación provee teorías de aprendizaje.

Desde la postura de la psicología cognitiva otro elemento importante en este proceso de enseñar es la competencia, facultad que tiene las personas producto de un proceso de experiencias vivenciadas y que le permite representar la realidad apelando a estrategias que se sustenta en la comprensión del hecho, fenómeno u objeto de estudio.

Desde la psicología cognitiva el docente en su proceso de enseñanza considera, según Tobón (2015, p. 84), que toda actividad humana se manifiesta en contextos particulares y específicos; la competencia comprende procesos, conocimientos, estrategias cognitivas y esquemas; $\mathrm{n}$ el desempeño académico intervienen factores internos y externos, y las personas tenemos diferentes maneras de procesar la información y esto se relaciona con el contexto, la herencia y el progreso cognitivo.

Los conceptos sobre enseñanza expuestos nos llevan a señalar la responsabilidad ética y social que posee el docente en el proceso de aprendizaje del estudiante. El docente es el personaje que plantea, planifica y decide a través del conocimiento, medios tecnológicos y actividades programadas oportunamente, la ruta académica que debe de seguir el estudiante para alcanzar el perfil deseado y establecido por la misma universidad. El profesor es el líder académico por la solvencia pedagógica y cultural que posee, su obra ingente es de corte social porque sus actos pedagógicos van a contribuir a la formación de una humanidad más humana y mejor preparada para servir a la sociedad. 


\section{Enseñanza de la Filosofía}

El hombre es una realidad y la enseñanza de la Filosofía es una realidad sustancial en la formación académica de los estudiantes. Donde ellos, asisten a la universidad para empezar una aventura intelectual que satisfaga sus necesidades intelectivas, conocimiento y otras capacidades propias de su virtud psico-orgánica (Zubiri, 2006, p.7).

Existen conceptos que destacan la enseñanza de la Filosofía, siendo uno de ellos, Gaos (1956), quien expone que la enseñanza universitaria debe, sobre todo, enseñar a trabajar de forma personal y originalidad. En relación a la Filosofía, lo más importante es utilizar los grandes temas para que se inicien los estudiantes en el filosofar (p.14). Los grandes temas filosóficos, sacuden las ideas y el pensamiento para así superar la mezquindad del alma y comprender la realidad natural y artificial que el hombre viene creando.

Salazar (1967) plantea que enseñar Filosofía no significa hacer proselitismo, el docente contribuye en el sentido que el estudiante tome conciencia de su propio ser, de sus alcances y limitaciones, como un ser que existente, de su condición y puesto en la realidad a partir de lo cual orienta su conducta (p. 40). La filosofía tiene una finalidad humanista.

Obiols (2002) refiere que la enseñanza filosófica es una actividad formativa, educativa, y la labor de enseñanza como una instancia del filosofar. El autor exige que el docente universitario tiene que ser investigador y su labor no es enseñar y controlar la cantidad de información que posee un estudiante. La enseñanza de la Filosofía exige la puesta de seminarios y que el estudiante debe ir aprendiendo a desarrollar una tarea hasta consolidar su producción académica (p. 62). La enseñanza de la Filosofía es una práctica filosófica necesaria para transitar y existir en este mundo. Como también nos acerca a estudiar y comprender el devenir de la ciencia, saca a la luz los aportes del conocimiento científico (Izquierdo et al., 2016, p. 14).

En suma, para terminar este documento, la enseńanza de la Filosofía promueve el desarrollo de un conjunto de capacidades como: la capacidad para analizar y sintetizar; expresar sus ideas con claridad a través de la comunicación oral y escrita; resolver los problemas cotidianos que enfrenta en su contexto; desarrollar el pensamiento crítico, reflexivo y la autocrítica; la capacidad investigativa; formar y trabajar en equipo; mejorar su actitud para asumir compromisos dentro de los cánones de la ética. Así como utilizar el conocimiento como un medio en la acción social; manifestar la disposición por la investigación; la autonomía e iniciativa social, y valorar la educación como proceso permanente e instrumento de cambio social.

La enseñanza de la Filosofía debe ser entendida como un proceso que busca orientar al hombre hacia los parámetros humanísticos, filosofar es el derrotero en esta dinámica académica que significa aprender a aprender, como aprender a aprender es aprender a pensar.

\section{Método}

El estudio es teórico refiere a una investigación documental de fuentes que permite el estudio del conocimiento sobre una temática específica cuya finalidad es dar cuenta del material documental sometido al análisis con el único propósito de revisar de manera detallada documentos que permitirán comprender su aporte (Londoño et al., 2014, p. 10).

\section{Resultados}

Considerando los conceptos de enseńanza y, de manera particular, de la enseñanza de la filosofía, como aspectos determinantes y complementarios de estudio, se precisa lo siguiente:

- La enseñanza de la filosofía es de carácter formativo y, para ello se hace necesario la lectura y el análisis de tratados filosóficos como la orientación pedagógica del docente para que así, el estudiante reflexione sobre su persona y el papel que desempeñará en la sociedad. 
- La enseńanza es un proceso de planificación que tiene como norte la competencia y/o el objetivo de aprendizaje. El docente que asume la responsabilidad de gestionar la asignatura de filosofía debe tener solvencia académica, capacidad investigativa para orientar la producción académica del estudiante, conocimiento y manejo de medios digitales, aplicación de métodos didácticos acorde a las necesidades cognitivas del estudiante, estos métodos de enseñanza han de ser activos.

- La temática u objeto de estudio debe de contrastarse con la realidad y así evitar la memorización y la especulación cognitiva. Es de necesidad pedagógica la determinación del contexto en el cual se va a actuar, conocer los problemas y las necesidades de la realidad es el punto de partida y el horizonte de la educación formativa.

- Se destaca el aporte de la psicología cognitiva, que explica la teorización representación-contexto y se concluye que la enseñanza de la filosofía debe orientarse a desarrollar competencias, bajo este enfoque el conocimiento o la información está acorde al contexto.

Finalmente, concluimos que la enseñanza de la filosofía como disciplina académica y muy propia contribuye con el proceso formativo del estudiante y al desarrollo de un conjunto de capacidades señaladas líneas arriba.

\section{Conclusión}

La filosofía es una disciplina académica y su desarrollo en el campo educativo es de vital importancia porque contribuye con la etapa formativa del estudiante. Para estos tiempos donde la sociedad cambia de manera acelerada y la tecnología de la informática y comunicación cambia el devenir de la educación y otras actividades humanas, la enseñanza de la filosofía conduce al estudiante a desarrollar un conjunto de capacidades que serán de utilidad en su vida futura en lo personal y profesional. La filosofía predispone al hombre a comprenderse como persona y a valorar la realidad social, natural y desconfía de toda postura totalitaria y dogmática.

La enseñanza de la filosofía debe ser asumida por un profesional de solvencia académica e investigativa, que conozca de métodos propios a la necesidad cognitiva de los estudiantes; valore el contexto fuente de problemas y necesidades que sirven de referencia para orientar la formación académica. La enseñanza exige una relación horizontal dentro de los parámetros del respeto y la tolerancia académica, generando relaciones democráticas entre el docente y los estudiantes. Asimismo, promueve la formación humanística, desarrolla la sensibilidad y emoción social, y el compromiso con el futuro de la sociedad.

\section{Referencias}

Álvarez, S. (1984). Planificación del currículo. Universitaria.

De Cols, S. (1976). Planeamiento del proceso de enseñanza-aprendizaje. Marymar.

Freire, P. (2004). Pedagogía de la autonomía. Paz y Tierra.

Gambra, R. (1989). Historia sencilla de la Filosofía. RIALP.

Gaos, J. (1956). La Filosofía en la universidad. Universidad Autónoma de México.

Izquierdo, M., García, A., Quintanilla, M., y Adúriz, A. (2016). Historia, Filosofía de las Ciencias: Aportes para la formación del profesorado de ciencias. Universidad Distrital Francisco José de Caldas. http://laboratoriogrecia. cl/wp-content/uploads/2016/09/historia_filosofia_y_didactica_de_las_ciencias_aportes_para_la_formacion_ del_profesorado_de_ciencias.pdf

Londoño, O., Maldonado, L., y Calderón, L. (2014). Guias para construir estados del arte. International Corporation of Networks of knowledge. http://iconk.org/docs/guiaea.pdf

Montanelli, I. (1985). Historia de los griegos. Plaza \& Janes Editores. 
Obiols, G. (2002). Una Introducción a la Enseñanza de la Filosofía. Fondo de Cultura de Argentina.

Salazar, A. (1967). Didáctica de la Filosofía. Arica.

Tobón, S. (2015). Formación integral y competencias. MACRO.

Tünnermann, C. (2003). La universidad Latinoamericana ante los retos del siglo XXI. Unión de Universidades de América Latina, A.C.

Zubiri, X. (2006). Tres dimensiones del ser humano: individual, social, histórica. Alianza Editorial - Fundación Xavier Zubiri.

\section{Notas al final}

1 Licenciado en Filosofía y Doctor en Educación. Desde hace diez años ejerce la docencia universitaria en la Facultad de Pedagogía de la Universidad Enrique Guzmán y Valle del Perú y en la escuela Profesional de la Universidad Nacional Mayor de San Marcos. Asimismo, ejerció la docencia en diversas instituciones educativas de Educación Básica Regular en las áreas de Ciencias Sociales de Lima.

2 Es Magíster en Investigación, Organización e Innovación de las Instituciones Educativas, UNED, España y docente de la Facultad de Pedagogía y Cultura Física de la Universidad Enrique Guzmán y Valle del Perú. 